\title{
Desempenho de cultivares de batata sob diferentes espaçamentos em solo naturalmente infestado com Ralstonia solanacearum
}

\author{
Agnaldo DF Carvalho; Carlos Alberto Lopes; Carlos Francisco Ragassi \\ Embrapa Hortaliças, Brasília-DF, Brasil; agnaldo.carvalho@embrapa.br; carlos.lopes@embrapa.br; carlos.ragassi@embrapa.br
}

\begin{abstract}
RESUMO
Nos últimos anos, diversas cultivares nacionais de batata foram lançadas, tais como BRSIPR Bel e BRS Camila, como alternativas às cultivares importadas tradicionalmente cultivadas no Brasil. Avaliou-se o comportamento das cultivares BRSIPR Bel, BRS Camila e Agata quando plantadas em quatro espaçamentos entre batatas-semente na linha $(15,20,25$ e $30 \mathrm{~cm})$ em um campo naturalmente infestado com Ralstonia solanacearum em Brasília-DF. O delineamento experimental foi de parcelas subdivididas com quatro repetições, sendo a parcela composta pelos diferentes espaçamentos e a subparcela pelas cultivares. Aos 59 dias após o plantio (DAP), a incidência de plantas com sintomas de murcha bacteriana foi avaliada e, na colheita, (116 DAP), foram avaliados: massa total de tubérculos, massa de tubérculos comerciais, número total de tubérculos e número de tubérculos comerciais. 'BRSIPR Bel', 'Agata' e 'BRS Camila' apresentaram diferentes níveis de suscetibilidade à murcha bacteriana, de 20, 30 e $80 \%$ de plantas sintomáticas aos 59 DAP, respectivamente. 'BRS Camila' apresentou produtividade inferior à 'BRSIPR Bel' e 'Agata'. Não houve efeito significativo do espaçamento de plantio sobre as variáveis mensuradas, mas 'BRSIPR Bel' e 'Agata' demonstraram um maior nível de resistência que 'BRS Camila', que se traduziu em maior produtividade nas condições avaliadas.
\end{abstract}

Palavras-chave: Solanum tuberosum, murcha bacteriana, resistência genética, sistema de produção.

\begin{abstract}
Performance of potato cultivars under different planting spacing in a naturally-infested soil by Ralstonia solanacearum

In recent years, Brazilian potato cultivars were released, such as BRSIPR Bel and BRS Camila, as alternatives to the imported cultivars, traditionally planted in Brazil. We evaluated the cultivars BRSIPR Bel, BRS Camila and Agata growing under four planting spacing $(15,20,25$ and $30 \mathrm{~cm}$ among seeds in line) in a field naturally infested with Ralstonia solanacearum in Brasilia, Brazil. The experimental design was a split plot with four replications, spacing as plots and cultivars as subplots. At 59 days after planting (DAP), the incidence of plants with symptoms of bacterial wilt was evaluated and during harvest, at 116 DAP, total mass of tubers, mass of marketable tubers, total number of tubers, and number of marketable tubers were evaluated. 'BRSIPR Bel', 'Agata' and 'BRS Camila' presented susceptibility levels to bacterial wilt of 20,30 and $80 \%$ of symptomatic plants at $59 \mathrm{DAP}$, respectively. In response to a higher bacterial wilt susceptibility, 'BRS Camila' had the lowest yield. No effect of plant spacing was observed. 'BRSIPR Bel' and 'Agata' had a higher resistance level in comparison to 'BRS Camila', which led to a higher productivity under the evaluated conditions.
\end{abstract}

Keywords: Solanum tuberosum, bacterial wilt, resistance, production system.

(Recebido para publicação em 12 de fevereiro de 2016; aceito em 10 de abril de 2017) (Received on February 12, 2016; accepted on April 10, 2017)

\begin{abstract}
A murcha bacteriana ou murchadeira, causada por Ralstonia solanacearum, é uma das principais doenças da batata (Solanum tuberosum) no Brasil e em outras regiões de clima tropical e subtropical. Seu controle é muito difícil e, quando cultivares muito suscetíveis são plantadas sob condições ambientais favoráveis à doença (alta temperatura e alta umidade), as perdas podem ultrapassar 50\% (Lopes, 2005).

Embora o uso de cultivares resistentes seja considerado o método mais eficiente de controle de doenças, principalmente por ser de fácil adoção pelos
\end{abstract}

agricultores e não onerar os custos de produção (Yuliar \& Toyota, 2015), ele praticamente não tem sido utilizado no caso da murcha bacteriana da batata. Isso se deve ao fato de a genética da resistência no germoplasma já explorado ser complexa, devido ao nível de ploidia da batata (tetraplóide), e porque os níveis de resistência encontrados são baixos e pouco estáveis, no tempo e no espaço, em virtude da alta variabilidade do patógeno (Silveira et al., 2007; Muthoni et al., 2012). Essas dificuldades têm desestimulado as pesquisas neste tema, motivo pelo qual se frustraram as poucas investidas iniciadas da década de 1970, com mais recente indicativo de que avanços consideráveis só serão possíveis por meio de transgenia (Patil et al., 2012). Embora altos níveis de resistência não estejam disponíveis nas cultivares mais plantadas no Brasil, nota-se que níveis intermediários de resistência podem ser úteis dentro do conjunto de medidas para o controle integrado da doença (Montenegro-Coca et al., 2012). Mesmo que não tenham sido selecionadas sob pressão de seleção, há vários relatos de níveis diferenciados de resistência entre cultivares de batata 
em várias regiões produtoras do mundo (Nielsen \& Haynes, 1960; Tung et al., 1990; Lopes et al., 1993).

Nos últimos anos, cultivares nacionais de batatas foram lançadas, tais como BRSIPR Bel (Pereira et al., 2015), pela parceria entre Embrapa Clima Temperado, Embrapa Hortaliças e IAPAR, e BRS Camila (parceria entre Embrapa Hortaliças e Clima Temperado) como alternativas ao plantio das cultivares importadas, tradicionalmente cultivada no Brasil. A cultivar Agata é a mais plantada no Brasil (ABBA, 2010), de origem holandesa e, portanto, dependente da importação de batata-semente. Por serem cultivares novas, é importante que se conheça seu desenvolvimento em diferentes espaçamentos, visto que a produtividade é dependente do número de hastes, que varia de cultivar para cultivar. O objetivo deste trabalho foi avaliar o comportamento dessas cultivares quando plantadas em quatro espaçamentos diferentes em um terreno naturalmente infestado com Ralstonia solanacearum em Brasília-DF.

\section{MATERIAL E MÉTODOS}

O experimento foi conduzido no setor de campos experimentais da Embra-

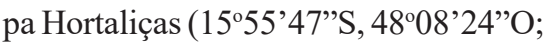
altitude $998 \mathrm{~m}$ ) de junho a outubro de 2015, em área com histórico de ocorrência de murcha bacteriana em batata e tomate, cujo inóculo foi identificado como pertencente à raça 1 , biovar 1 , filotipo 2 por meio de testes bioquímicos e análise de PCR multiplex, realizados na Embrapa Hortaliças (Lopes, 2005). A densidade do inóculo presente no solo não foi quantificada. Foram avaliadas três cultivares de batata (BRSIPR Bel, BRS Camila e Agata) em quatro diferentes espaçamentos entre batatas-semente $(15,20,25$ e $30 \mathrm{~cm})$.

O delineamento experimental foi blocos casualizados em esquema de parcelas subdivididas com quatro repetições, sendo as parcelas constituídas pelos diferentes espaçamentos e as subparcelas pelas cultivares de batata. Foram utilizados tubérculos sementes (tipo II: diâmetro entre 40 e $50 \mathrm{~mm}$ ), armazenados por quatro meses em câmara fria à temperatura de $4,0 \pm 0,5^{\circ} \mathrm{C}$. A parcela experimental foi constituída por linhas de três metros de comprimento, com espaçamento entre linhas de $80 \mathrm{~cm}$. $\mathrm{O}$ número de tubérculos semente por parcela variou em função do espaçamento adotado: dez sementes para o espaçamento de $30 \mathrm{~cm}$ entre tubérculos, doze sementes para o espaçamento $25 \mathrm{~cm}$, quinze sementes para o espaçamento 20 $\mathrm{cm}$ entre tubérculos e 20 sementes para o espaçamento $15 \mathrm{~cm}$ entre tubérculos.

O plantio foi realizado em 19 de junho de 2015. A adubação de plantio foi realizada com $90 \mathrm{~kg} / \mathrm{ha}$ de ureia $(41 \mathrm{~kg} /$ ha N); $1450 \mathrm{~kg} /$ ha de superfosfato triplo $\left(661 \mathrm{~kg} / \mathrm{ha} \mathrm{P}_{2} \mathrm{O}_{5}\right)$ e $90 \mathrm{~kg} / \mathrm{ha}$ de cloreto de potássio $\left(54 \mathrm{~kg} / \mathrm{ha} \mathrm{K}_{2} \mathrm{O}\right)$. A irrigação foi realizada por meio de aspersor tipo canhão. A amontoa foi realizada manualmente com uso de enxadas aos 25 dias após o plantio (DAP), sendo a adubação de cobertura realizada no momento da amontoa na dosagem de 120 $\mathrm{kg} / \mathrm{ha}$ de nitrato de amônio (41 kg/haN).

A avaliação da doença foi realizada em intervalos semanais após o aparecimento dos primeiros sintomas, observados a partir de sete dias após a amontoa. Aos 59 DAP, a incidência de plantas com sintomas de murcha bacteriana (IMB) foi avaliada pela relação entre o número de plantas que apresentavam sintomas e o número total de plantas na parcela. Esta leitura foi escolhida porque coincidiu com o maior vigor vegetativo das plantas e foi a que proporcionou a melhor diferenciação entre os genótipos.
Para essa avaliação, uma planta foi considerada sintomática quando apresentou mais de $50 \%$ das ramas murchas.

A colheita foi realizada aos 116 DAP e os seguintes caracteres foram avaliados: massa total de tubérculos (MTT, kg/parcela); massa de tubérculos comerciais (MTC, kg/parcela dos tubérculos com diâmetro acima de $45 \mathrm{~mm}$ ), número total de tubérculos (NTT) e número de tubérculos comerciais (NTC, diâmetro acima de $45 \mathrm{~mm}$ ). Somente foram recolhidos para as mensurações os tubérculos aparentemente sadios, visto que plantas com infecção precoce produziram tubérculos com necrose nos olhos que, na maioria das vezes, evoluíram para apodrecimento total por conta da invasão de microrganismos saprófitas.

Por não apresentarem efeito de aditividade do modelo, todas as variáveis precisaram ser transformadas para $\sqrt{\mathrm{x}+0,5}$. As análises de variância, correlação fenotípica e teste de médias (Tukey a 5\% de significância) foram analisadas com o aplicativo computacional SAS v. 9.2 (SAS, 2008).

\section{RESULTADOS E DISCUSSÃO}

A condição ambiental registrada durante a execução do experimento, em especial alta temperatura, com máximas diárias em torno de $30^{\circ} \mathrm{C}$ e alta umidade do solo, visto que o cultivo foi irrigado, favoreceu a manifestação da murcha

Tabela 1. Correlação de Pearson para os caracteres massa total de tubérculos (MTT, kg/ parcela), massa de tubérculos comerciais (MTC, kg/parcela), número total de tubérculos (NTT / parcela), número de tubérculos comerciais (NCT/parcela) e incidência de murcha bacteriana (IMB, porcentagem de plantas com sintoma aos 59 dias após o plantio) em batata, avaliadas em Brasília-DF, ano de 2015 \{Pearson's correlation for the characteristics total tuber weight (MTT, kg/plot), weight of commercial tubers (MTC, kg/plot), total number of tubers (NTT/ plot, number of marketable tubers (NCT /plot) and bacterial wilt incidence (IMB, percentage of simptomatic plants at 59 days after planting)\}. Brasília, Embrapa Hortaliças, 2015.

\begin{tabular}{lcccc}
\hline & MTC & NTT & NCT & IMB \\
\hline MTT & $0,97^{* *}$ & $0,96^{* *}$ & $0,96^{* *}$ & $-0,90^{* *}$ \\
MTC & & $0,88^{* *}$ & $0,97 * *$ & $-0,85^{* *}$ \\
NTT & & $0,93^{* *}$ & $-0,89 * *$ \\
NCT & & & & $-0,84 * *$ \\
\hline
\end{tabular}

**Significativo a $1 \%$ de probabilidade pelo teste $t$ de Student (significant at $1 \%$ probability by Student's $t$ test). 
bacteriana de maneira visualmente uniforme na área experimental, o que permitiu distinguir quanto à reação das três cultivares aos 59 DAP.

A análise de variância para as variáveis incidência de plantas com sintomas de murcha bacteriana (IMB), massa total de tubérculos (MTT); massa de tubérculos comerciais (MTC), número total de tubérculos (NTT) e número de tubérculos comerciais (NTC) demonstrou haver efeito altamente significativo $(p \geq 0,01)$ das cultivares avaliadas para todas as variáveis. $\mathrm{O}$ espaçamento utilizado, assim como a interação espaçamentos $\mathrm{X}$ cultivares, não apresentaram efeito significativo ( $p \geq 0,05)$ e, dessa forma, seus desdobramentos não são apresentados nos resultados.

Esperava-se, por hipótese, que o espaçamento entre plantas afetasse tanto a incidência de murcha bacteriana quanto a produtividade. A produtividade seria afetada pela diferença na quantidade de plantas por área, enquanto a incidência de murcha bacteriana poderia ser afetada pelo processo de disseminação da bactéria entre raízes de plantas próximas (Kelman \& Siqueira, 1965), que poderia ser intensificado pelo maior adensamento de plantas.

A cultivar BRSIPR Bel apresentou a menor suscetibilidade à murcha bacteriana dentre os materiais avaliados, $o$ que foi verificado com base na porcentagem de plantas com sintoma de murcha aos 59 dias após o plantio (Figura 1). 'Agata' apresentou cerca de duas vezes mais plantas murchas que BRSIPR Bel; e BRS Camila, a mais afetada, cerca de quatro vezes mais plantas murchas em comparação a 'BRSIPR Bel'. A cultivar BRSIPR Bel, dessa forma, destacou-se por apresentar um nível superior de resistência à cultivar Agata, tradicionalmente plantada.

A massa média de tubérculos totais e comerciais por parcela, considerando o experimento como um todo, foi de 3,96 e 2,67 kg, respectivamente. Essa produção convertida para $t /$ ha equivale a 16,5 e 11,1, respectivamente. São valores muito baixos ao se considerar a produtividade média da batata no Brasil (29,3 kg/ha, IBGE, 2015), mas razoáveis ao se considerar uma incidência média geral de $42 \%$ de plantas com sintomas de murcha bacteriana. O menor coeficiente de variação experimental obtido foi de $8,12 \%$ para IMB, e o maior, de $23,81 \%$ para NTC. Esses valores são próximos aos de outros experimentos de campo com batata (Costa et al., 2015), assim como aos de trabalhos que avaliaram a incidência de murcha bacteriana (Oliveira et al., 2014).

A cultivar BRS Camila apresentou índices inferiores para os caracteres relacionados à produção total e comercial (Figuras 2 e 3) nas condições avaliadas. 'BRSIPR Bel' se destacou por apresentar valores de caracteres componentes da produção similares aos de 'Agata', os quais foram cerca de três vezes superiores em relação à 'BRS Camila'. Isso ocorreu possivelmente devido à menor suscetibilidade à murcha bacteriana das duas primeiras cultivares em relação à 'BRS Camila' (Figura 1).

Na Tabela 1, estão apresentados os resultados das correlações de Pearson entre os caracteres MTT, MTC, NTT, NTC e IMB. Verifica-se correlação positiva, altamente significativa $(r \geq 0,88$, $\mathrm{p}<0,01)$ entre os caracteres MTT, MTC, NTT e NTC. Já, os valores de correlação entre as variáveis componentes de produção com o IMB são negativos e altamente significativos $(r \geq-0,84$, $\mathrm{p}<0,01)$. Esses resultados ressaltam a capacidade de redução da produtividade em condições de alta infestação de murcha bacteriana, além da importância

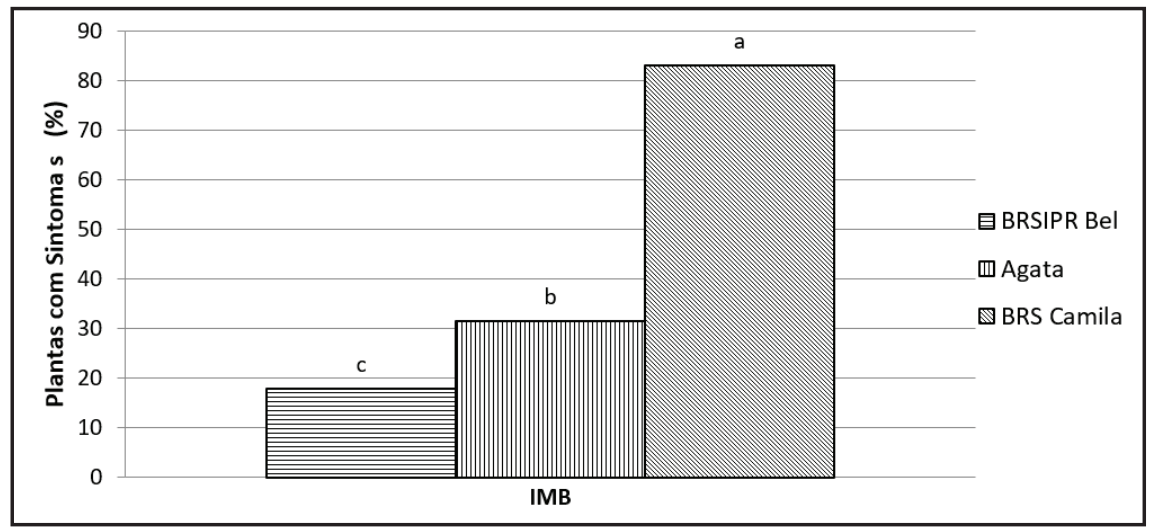

Figura 1. Porcentagem de plantas apresentando sintoma de murcha bacteriana (Ralstonia solanacearum) aos 59 dias após o plantio, para três cultivares de batata em solo naturalmente infestado. Letras diferentes indicam diferença estatística por Tukey $5 \%$ (percentage of plants with bacterial wilt symptoms, evaluated 59 days after planting, of three potato cultivars in a field naturally infested with Ralstonia solanacearum. Different letters indicate significant differences by Tukey 5\%). Embrapa Hortaliças, Brasília, 2015.

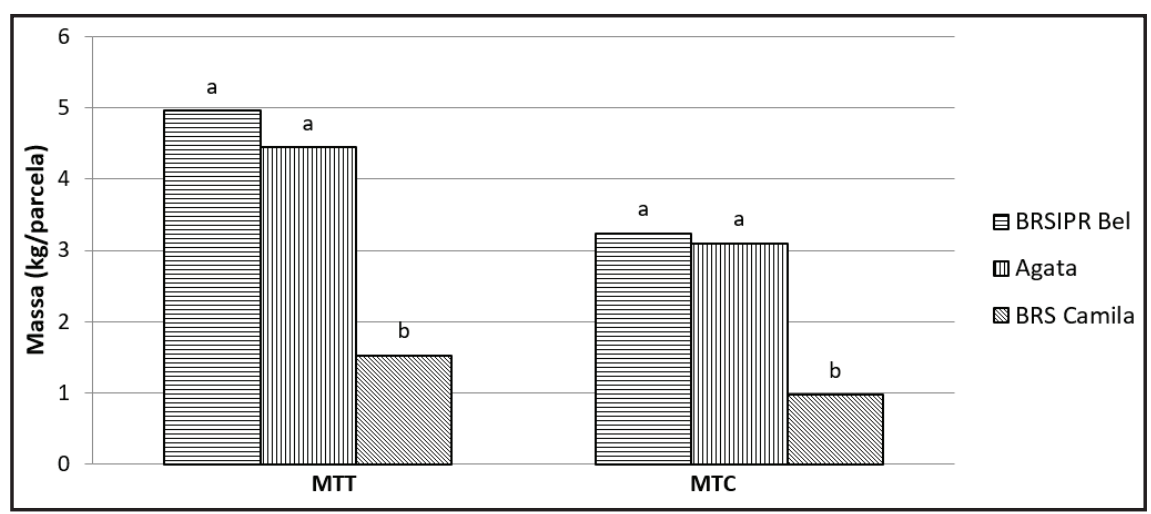

Figura 2. Massa total de tubérculos (MTT) e massa de tubérculos comerciais (MTC), por parcela, de três cultivares de batata em solo naturalmente infestado com Ralstonia solanacearum. Letras diferentes indicam diferença estatística por Tukey 5\% \{total (MTT) and marketable yield (MTC), per plot, of three potato cultivars grown in a field naturally infested with Ralstonia solanacearum. Different letters indicate significant differences by Tukey 5\% . Embrapa Hortaliças, Brasília, 2015. 


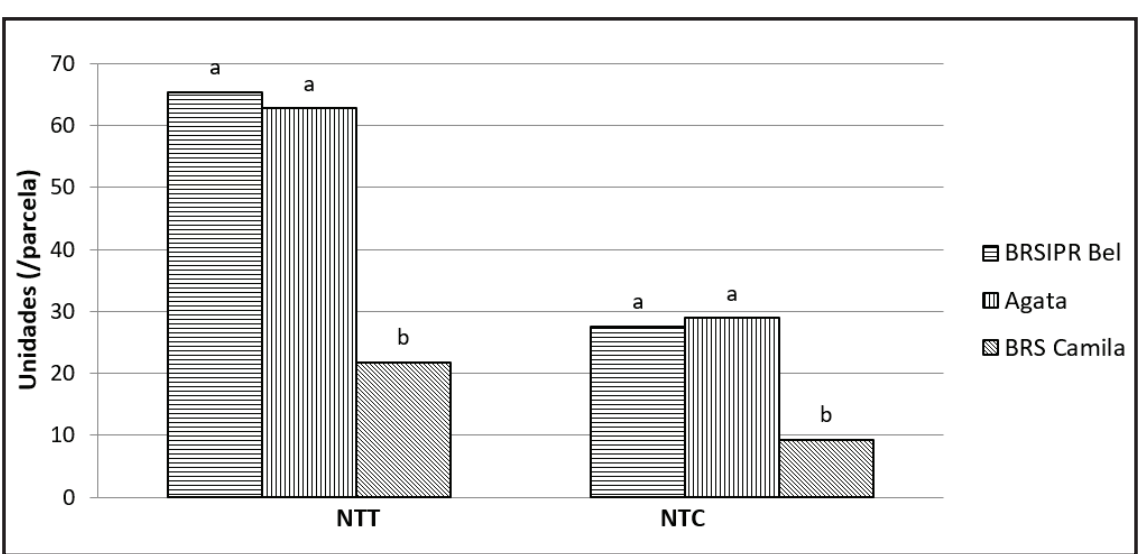

Figura 3. Número total de tubérculos (NTT) e de tubérculos comerciais (NTC) por parcela, de três cultivares de batata em solo naturalmente infestado com Ralstonia solanacearum. Letras diferentes indicam diferença estatística por Tukey 5\% \{total number (NTT) and number of marketable tubers (NTC) per plot, of three potato cultivars grown in a field naturally infested with Ralstonia solanacearum. Different letters indicate significant differences by Tukey $5 \%$. Embrapa Hortaliças, Brasília, 2015.

dessa doença para a cultura da batata.

Agata ainda é a cultivar mais plantada em todas as regiões produtoras no Brasil. Em 2010, essa cultivar foi plantada em torno de $55 \%$ da área cultivada com batata, de acordo com a Associação Brasileira da Batata (ABBA, 2010). Essa cultivar destaca-se pela sua grande adaptabilidade a diferentes climas, alta produtividade e ótima aparência de tubérculos, embora sua qualidade culinária seja prejudicada pela baixa quantidade de sólidos solúveis em seus tubérculos. Embora não seja considerada uma cultivar resistente à murcha bacteriana, percebe-se que ela apresenta algum grau de resistência, o que foi atestado pelos resultados aqui apresentados, que estão em concordância com a hipótese de Tung et al. (1990), que afirmam que a resistência à murcha bacteriana se manifesta em função da adaptabilidade do genótipo a determinada região. Também desta maneira, pode-se inferir que a cultivar BRSIPR Bel, com aptidão para a indústria, apresenta adaptabilidade regional superior à BRS Camila.

Extensa busca de fontes de resistência à murcha bacteriana já foi realizada em bancos de germoplasma de batata em todo mundo. Quando encontrada, a resistência é poligênica e parcial, não conferindo proteção suficiente para ser usada como tática única de controle. Mesmo não havendo registro de cultivares de batata com resistência total à doença, é fácil constatar que mesmo um nível moderado de resistência pode ser útil dentro do contexto do manejo integrado. É interessante registrar que, em alguns casos, materiais que não foram melhorados para resistência à doença têm se comportado igual ou melhor do que clones experimentalmente selecionados para tal. Assim, 'Ontário' sobressaiu-se entre outras cultivares nos EUA (Nielsen \& Haynes, 1960) e em Papua Nova Guiné (Tomlinsom \& Gunther, 1986, citados por French, 1994). Da mesma forma, 'Prisca' foi a cultivar mais resistente dentre 9.000 genótipos avaliados (Nielsen \& Haynes, 1960), motivo pelo qual foi uma das mais importantes cultivares em Madagascar por muitos anos. No Brasil, a cultivar Achat foi a única que apresentou certo grau de resistência quando avaliada em solo naturalmente infestado em Brasília, em comparação com clones obtidos no CIP (Lopes \& Giordano, 1983) ou com cultivares nacionais selecionadas no Rio Grande do Sul, onde a murchadeira é endêmica (Lopes et al., 1993). A resistência à murcha bacteriana, entretanto, não foi suficientemente relevante para evitar que 'Achat', que dominou o mercado brasileiro por vários anos das décadas de 1980 e 1990, fosse substituída por outras de melhor aparência, como 'Monalisa' e, posteriormente, 'Agata'.

As cultivares BRSIPR Bel, Agata e BRS Camila apresentam diferentes níveis de suscetibilidade à murcha bacteriana, de forma crescente da primeira à última cultivar mencionada. Quanto aos caracteres componentes da produção, 'BRSIPR Bel' e 'Agata' apresentam desempenho similar e superior ao de 'BRS Camila' em solo naturalmente infestado com Ralstonia solanacearum. Os diferentes níveis de espaçamento entre batatas-semente na linha estudados não influenciaram as características avaliadas e não apresentaram interação com as diferentes cultivares estudadas.

\section{REFERÊNCIAS}

ABBA - Associação Brasileira da Batata. 2010. Brasil, atuais variedades. Batata Show 28: (artigo de capa)

COSTA, CFA; MELO, PCT; RAGASSI, CF; LAZZARINI, PRC; FERRONATO, EM; MARTINS, EAS; ARAÚJO, TH. 2015. Crescimento da batateira em sistema de preparo profundo de solo e sucessão de poáceas. Horticultura Brasileira 33: 051-058.

FRENCH, ER. 1994. Strategies for integrated control of bacterial wilt of potatoes. In: HAYWARD, AC; HARTMAN, GL (eds). Bacterial Wilt: The disease and its causative agent, Pseudomonas solanacearum. Wallingford: CAB. p.199-207.

INSTITUTO BRASILEIRO DE GEOGRAFIA E ESTATÍSTICA (IBGE). 2015. Levantamento Sistemático da Produção Agrícola (LSPA) - Setembro $2015<$ http://www.sidra.ibge. gov.br/bda/prevsaf/default.asp? $\mathrm{t}=4 \& \mathrm{z}$ $=\mathrm{t} \& \mathrm{o}=26 \& \mathrm{u} 1=1 \& \mathrm{u} 2=1 \& \mathrm{u} 3=1 \& \mathrm{u} 4=1>$

KELMAN, A; SIQUEIRA, L. 1965. Root-toroot spread of Pseudomonas solanacearum. Phytopathology 55: 304-309.

LOPES, CA; GIORDANO, LB. 1983. Avaliação da resistência de oito clones e três cultivares de batata (Solanum tuberosum L.) à murchabacteriana causada por Pseudomonas solanacearum. Horticultura Brasileira 1: 33-35.

LOPES, CA. 2005. Murchadeira da batata. Itapetininga: Associação Brasileira da Batata. $66 \mathrm{p}$.

LOPES, CA; LIMA, BJC; BUSO, JA. 1993. Reaction of Brazilian potato varieties to bacterial wilt. Biological \& Cultural Tests 8: 38 .

MONTENEGRO-COCA, D; RAGASSI, CF; LOPES, CA. 2012. Utilização de esterco como medida auxiliar no controle da murcha bacteriana em genótipos de batata. Revista Latinoamericana de la papa 17: 152-169.

MUTHONI, J; SHIMELIS, H; MELIS, R. 2012. Management of bacterial wilt [Ralstonia solanacearum Yabuuchi et al., 1995] of potatoes: Opportunity for host resistance in Kenya. Journal of Agricultural Science 4: 64-78.

NIELSEN, LW; HAYNES, FL. 1960. Resistance in Solanum tuberosum to Pseudomonas 
solanacearum. American Potato Journal 37 : 260-267.

OLIVEIRA, IT; LOPES, CA; MOURA, AB. 2014. Fruit yield and bacterial wilt symptoms on eggplant genotypes grown in soil infested with Ralstonia solanacearum. Horticultura Brasileira 32: 453-457.

PATIL, VU; GOPAL, J; SINGH, BP. 2012. Improvement for bacterial wilt resistance in potato by conventional and biotechnological approaches. Agricultural Research 1:299-316.

PEREIRA, AS; NAZARENO, NRX; SILVA, GO; BERTONCINI, O; CASTRO, CM; HIRANO,
E; BORTOLETTO, AC; TREPTOW, RO; DUTRA, LF; LIMA, MF; GOMES, CB; KROLOW, ACR; MEDEIROS, CAB; CASTRO, LAS; SUINAGA, FA; LOPES, CA; MELO, PE. 2015. BRSIPR Bel: cultivar de batata para chips com tubérculos de boa aparência. Horticultura Brasileira 1: 135-139.

SAS INSTITUTE Inc. 2008. SAS/STAT ${ }^{\circledR}$ 9.2: user's guide: statistics version 9.2. Cary, North Carolina, USA.

SILVEIRA, JRP; DUARTE, V; MORAES, MG; LOPES, CA; FERNANDES, JM; BARNI, V; MACIEL, JLN. 2007. Epidemiological analysis of clones and cultivars of potato in soil naturally infested with Ralstonia solanacearum biovar 2. Fitopatologia Brasileira 32: 181-188.

TUNG, PX; RASCO, ET; ZAAG, PV; SCHMIEDICHE, P. 1990. Resistance to Pseudomonas solanacearum in the potato: I Effects of sources of resistance and adaptation. Euphytica 45: 203-210.

YULIAR, YAN; TOYOTA, K. 2015. Recent trends in control methods for bacterial wilt diseases caused by Ralstonia solanacearum. Microbes and Environments 30: 1-11. 